\title{
Structure of ultrafine grained alloy A2024 after combined heat-deformation treatment
}

\author{
A. N. Petrova ${ }^{1}$, I. G. Shirinkina ${ }^{1}$, I. G. Brodova ${ }^{1, \dagger}$, L. Kaczmarek ${ }^{2}$, M. Stenglinski ${ }^{2}$ \\ †brodova@imp.uran.ru
}

${ }^{1}$ M.N. Mikheev Institute of Metal Physics of the Ural Branch of RAS, 18 S. Kovalevskoy st., 620990, Yekaterinburg, Russia

${ }^{2}$ Technical University of Lodz, 1/15 Stefanovskogo st., 90-924, Lodz, Poland

\begin{abstract}
The present work studies the effect of preliminary heat treatment on the features of ultra fine-grained (UFG) structure formation in $\mathrm{Al}-\mathrm{Cu}-\mathrm{Mg}$ alloy by means of high pressure torsion in Bridgman anvils. Heat treatment was carried out following two regimes: regime 1 included heating to a temperature of $500^{\circ} \mathrm{C}, 16$ hours and quenching in water, and regime 2 additionally included two-stage T6I6 aging: $120^{\circ} \mathrm{C}, 1.5$ hours and $160^{\circ} \mathrm{C}, 6$ hours, after quenching with water quenching after each stage. The number of revolutions of the anvil was $n=5,10$, which, according to the calculation, corresponded to the true logarithmic strain $e \approx 5.5,6.5$. It is shown that after the preliminary two-stage aging T6I6 of coarse-grained alloy fragmented grain/subgrain structure with high dislocation density was formed at $e=5.5$. The relaxation processes were suppressed by blocking of the grain boundaries by dispersed particles of the strengthening $S$ phase. It was shown that at $e=6.5$ alloy structure is refined to the nanolevel, and the process of dynamic dissolution of $S$ phase precipitates started parallel. It is accompanied by the appearance of defect-free grains and a mixed structure was formed. In the case of the torsion of hardened coarse-grained alloy, the main mechanism of grain refinement to $450 \mathrm{~nm}$ is dynamic recrystallization. At $e=6.5$ the dynamic aging of the supersaturated $\mathrm{Al}$ solid solution becomes the additional relaxation channel of the elastic energy and the hardness of the UFG alloy increases up to $3000 \mathrm{MPa}$.
\end{abstract}

Keywords: aluminum alloy, severe plastic deformation, heat deformation, structure, hardness.

\section{Структура ультрамелкозернистого сплава А2024 при комбинированной термодеформационной обработке}

\author{
Петрова А.Н. ${ }^{1}$, Ширинкина И. Г. ${ }^{1}$, Бродова И. Г. ${ }^{1, \dagger}$, Качмарек Л. ${ }^{2}$, Стеглински М. ${ }^{2}$ \\ tbrodova@imp.uran.ru
}

${ }^{1}$ Институт физики металлов УрО РАН им. М.Н. Михеева, ул. Софьи Ковалевской 18, 620990, Екатеринбург, Россия
2Технический университет города Лодзь, ул. Стефановского 1/15, 90-924, Лодзь, Польша

В работе рассмотрено влияние предварительной термической обработки на особенности формирования ультрамелкокристаллической (УМК) структуры при кручении под высоким квазигидростатическим давлением в наковальнях Бриджмена $\mathrm{Al}-\mathrm{Cu}-\mathrm{Mg}$ сплава. Термическая обработка проводилась по двум режимам: режим 1 включал нагрев до температуры $500^{\circ} \mathrm{C}, 16$ часов и закалку в воду, а режим 2 после закалки дополнительно включал двухстадийное старение Т6I6: $120^{\circ} \mathrm{C}, 1,5$ часа и $160^{\circ} \mathrm{C}, 6$ часов, после каждой стадии образцы закаливали в воду. Число оборотов наковальни составляло $n=5,10$, что по расчёту соответствовало истинной логарифмической деформации $e \approx 5.5,6.5$ в точках, лежащих на половине радиуса образца. Установлено, что предварительное двухстадийное старение крупнозернистого сплава способствует образованию фрагментированной зеренно-субзеренной структуры с высокой плотностью дислокаций при $e=5.5$ и задерживает релаксационные процессы за счет блокировки границ зерен/субзерен дисперсными частицами упрочняющей фазы $S$. Показано, что при $e=6.5$ происходит измельчение структуры сплава до наноуровня,, и параллельно идёт процесс динамического растворения частиц $S$ фазы, который сопровождается появлением бездефектных зерен и формированием смешанной структуры. В случае кручения закаленного крупнозернистого сплава основным механизмом измельчения структуры до 450 нм является динамическая рекристаллизация. При $e=6.5$ появляется дополнительный канал релаксации упругой энергии - динамическое старение пересыщенного $\mathrm{Al}$ твёрдого раствора, в результате которого твёрдость УМК сплава возрастает до 3000 МПа.

Ключевые слова: алюминиевый сплав, интенсивная пластическая деформация, термическая обработка, структура, свойства. 


\section{1. Введение}

Сплав A2024 относится к системе Al-Mg-Mn и широко применяется в качестве конструкционного материала, к которому предъявляются такие требования, как высокая удельная прочность и технологическая пластичность. Сплав является термически упрочняемым, и поэтому его механические характеристики можно регулировать, меняя режимы термической обработки [1 -4]. К настоящему времени разрабатываются режимы двухстадийного старения, варьируя которые можно менять морфологию и кинетику выделения упрочняющих фаз и регулировать величину упрочнения и прочность материала [5-7]. Так, авторы [7] предложили использовать режим двухстадийного старения Т6I6 для сплава А2024 с целью изменения химического состава частиц кристаллизационного происхождения, что позволило при незначительном увеличении прочностных характеристик повысить пластичность этого материала.

Несмотря на достигнутые успехи, проблема повышения прочности сплавов системы $\mathrm{Al}-\mathrm{Cu}-\mathrm{Mg}$ остается актуальной, и одним из путей ее решения является применение комбинированных термодеформационных обработок [8-12]. Работы последних лет показали, что структура и свойства сплавов с ультрамелкокристаллической (УМК) структурой, полученной методами интенсивной пластической деформации, зависит от начального структурного состояния, которое задается предшествующей термической обработкой материала.

В связи с этим, цель настоящей работы - выяснить влияние разной термообработки на закономерности структурообразования при ИПД сплава А2024.

\section{2. Материалы и методика исследования}

Материалом для исследования выбран промышленный алюминиевый сплав А2024 следующего химического состава (масс. \%): $\mathrm{Cu}-4,5 ; \mathrm{Mg}-0,4 ; \mathrm{Mn}-0,6 ; \mathrm{Si}-0,07$.

Материал подвергался нескольким режимам термической обработки. Режим 1 - нагрев до температуры $500^{\circ} \mathrm{C}$, 16 часов и закалка в воду. Режим 2 - закалка и последующее двухстадийное старение Т6I6: $120^{\circ} \mathrm{C}, 1,5$ часа и $160^{\circ} \mathrm{C}$, 6 часов, после каждой стадии нагрева и выдержки образцы быстро охлаждались в воде [7]. После обоих режимов термообработки образцы подвергались ИПД методом кручения в наковальнях Бриджмена (метод КВД). Деформирование дисков диаметром 10 мм и толщиной 0.75 мм осуществлялось со скоростью 1 об/мин при давлении $P=4$ ГПа и комнатной температуре. Число оборотов наковальни составляло $n=5,10$, что по расчёту соответствовало истинной логарифмической деформации $e \approx 5.5,6.5$ в точках, лежащих на половине радиуса образца.

Металлографические исследования образцов до и после деформации проведены с помощью оптического микроскопа "Neophot-32". Электронно-микроскопические исследования выполнены на электронных просвечивающих микроскопах (ПЭМ) JEM-200СХ и Philips СМ-30. Микротвердость измеряли прибором ПМТ-3 на половине радиуса образца, для определения среднего значения использовали 10 измерений.

\section{3. Результаты и их обсуждение}

Согласно приведенным выше режимам термической обработки, в состоянии 1 сплав представляет собой пересыщенный твердый раствор на основе алюминия, а в состоянии 2 - гетерофазный материал, в состав которого, помимо $\mathrm{Al}$ твердого раствора, входят упрочняющие фазы - алюминиды меди и магния. Структура сплава после двухстадийного старения по режиму Т6I6 показана на рис. 1. Согласно данным ПЭМ, в структуре наблюдается несколько видов алюминидов разных форм и размеров. На светлопольном изображении четко выявляются темные дисперсоиды Т-фазы размером $100-200$ нм, имеющие химический состав $\mathrm{Al}_{20} \mathrm{Cu}_{2} \mathrm{Mn}_{3}$ (рис. 1a) и более мелкие выделения $S$-фазы в виде тонких стержней (рис. 1b). На темнопольных снимках показано, что последние могут выстраиваться в длинные цепочки (рис. 1c) или располагаться на дисперсоидах T-фазы (рис. 1d). Последовательность стадий перехода от зонного к фазовому старению в сплаве А2024 подробно рассмотрена в ряде работ $[3,4,12-14]$ и здесь не обсуждается.

После кручения на 5 оборотов (e=5.5) формируется типичная деформированная структура с неравномерным деформационным контрастом внутри зерен, свидетельствующим о высоких микронапряжениях решетки и высокой плотности дислокаций (рис. 2). Средний размер зерен/субзерен, рассчитанный по темнопольным изображениям, составляет 200 нм. Анализ данных, приведенных на рис. 2, указывает, что структура сформировалась механизмом фрагментации. Дисперсные частицы алюминидов, расположенные на границах и в тройных стыках зерен, стабилизируют УМК фрагментированную структуру, препятствуя протеканию релаксационных

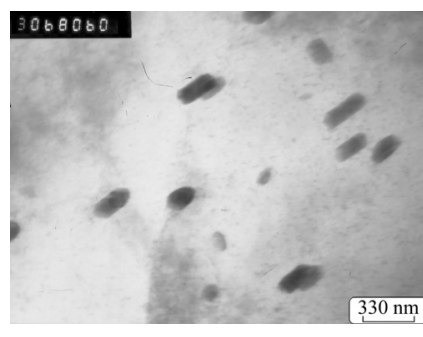

a

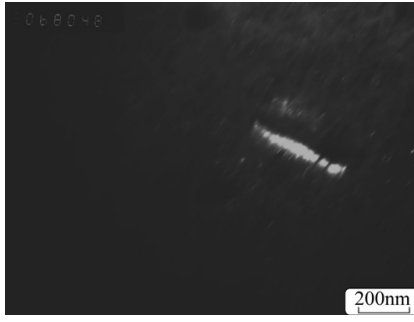

c

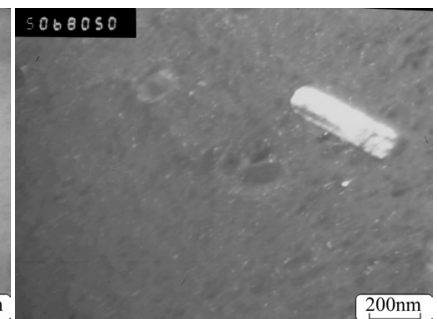

b

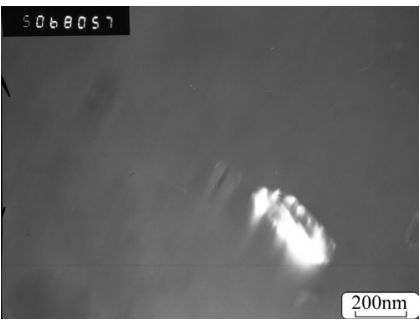

$\mathrm{d}$
Рис. 1. Микроструктура сплава после старения по режиму T6I6: (a,b) светлопольные изображения; (c) темнопольное изображение в рефлексе алюминида $g=(222)_{\mathrm{Al} 2 \mathrm{CuMg}}$; (d) темнопольное изображение в совместном рефлексе $T$ и $S$ фаз.

Fig. 1. TEM microstructure after the T6I6 ageing: $(\mathrm{a}, \mathrm{b})$ bright field images, (c) dark field image in phase reflection $g=(222)_{\mathrm{Al} 2 \mathrm{CuMg}}$; (d) dark field image in general reflection of $T$ and $S$ phases. 
процессов. Согласно контрасту на темнопольных снимках и дифракционной картине, в деформированной структуре после кручения на 5 оборотов эти фазы, размер которых не превышает 10-20 нм, сохраняются (рис. 2b).

Дальнейшее повышение накопленной деформации при $n=10$ (e=6.5) меняет характеристики деформированной структуры (рис. 3). Также выявляются зерна со сложным внутренним строением, различные по ширине и дефектности границы фрагментов и дислокационные скопления (рис. За). Как следует из темнопольных снимков, несколько уменьшается анизотропия зерен, а их средний размер приближается к наноуровню (рис. 3b). Наблюдается большой разброс зерен/субзерен по размерам от 200 до 25 нм. На фоне деформированных зерен, содержащих дислокации, появляются отдельные «чистые» зерна с низкой плотностью дефектов, которые образовались в результате прохождения динамической рекристаллизации. Появление таких локальных очагов бездислокационных зерен среди фрагментированной структуры неоднократно наблюдалось при ИПД алюминиевых сплавов ранее $[15,16]$. Из характера кольцевой дифракционной картины следует, что все рефлексы соответствуют решетке $\mathrm{Al}$ матрицы, а отражений от других фаз нет (рис. 3c). Отсутствие интерметаллидов также подтверждается электронно-микроскопическими данными.

Таким образом, можно считать, что в интервале $5.5<e<6.5$ параллельно с измельчением структуры происходит деформационное растворение упрочняющих фаз, и происходит формирование смешанной УМК структуры, состоящей из фрагментированных и рекристаллизованных зерен. Соотношения зон, занятых теми или иными зернами, меняются по сечению образцов, что связано с неодновременным протеканием процессов деформации и релаксации.

Изменения в структуре обработанного по режиму 2 сплава, обнаруженные при увеличении величины накопленной деформации, отражаются на твердости (рис. 4). Переход от крупнокристаллического в УМК состояние сплава сопровождается резким повышением микротвердости на $900 \mathrm{MПа}(n=5)$, которая практически не меняется, несмотря на дальнейшее деформирование материала $(n=10)$. Такой ход изменения твердости свидетельствует о перераспределении вкладов структурных элементов в общее упрочнение сплава. Если при $n=5$ основной вклад в упрочнение вносят большое количество дислокаций и большеугловые границы, то при $n=10$ сохраняется зернограничное упрочнение, а снижение дислокационного упрочнения компенсируется твердорастворным упрочнением.

Особенности структурообразования при кручении сплава, обработанного по первому режиму термической обработки, показаны на рис. 5. Так, при $n=10$ основными элементами исходно закалённой структуры являются зерна с низкой плотностью дефектов, ограниченные большеугловыми границами с полосчатым контрастом, а также небольшая доля деформационных фрагментов (рис. 5a,b). На рис. 5с показано распределение зерен по размерам, из которого следует, что структура образована зернами/субзёрнами, размер которых изменяется от 100 до 1200 нм при среднем размере 460 нм. По морфологическим признакам можно судить, что основным механизмом формирования УМК состояния является динамическая рекристаллизация. Образование УМК структуры, а также наличие дефектов инициируют диффузионный процесс распада пересыщенного твёрдого раствора, т.е. пластическая деформация закалённого сплава приводит к изменению его фазового состава. В результате деформационного старения из пересыщенного Al твердого раствора выпадают дисперсные упрочняющие фазы (рис. 5а). На рис. 5а эти сферические частицы размером менее 20 нм показаны на темнопольном снимке, снятом в совместном рефлексе $\theta$ и $S$ фаз. Из-за близких межплоскостных расстояний в решетках упрочняющих фаз $\theta$ и $S$, на темнопольных изображениях их трудно разделить, тем более, что, выпадая из твёрдого раствора в процессе деформации, они меняют свою морфологию и приобретают одинаковую глобулярную форму [10].

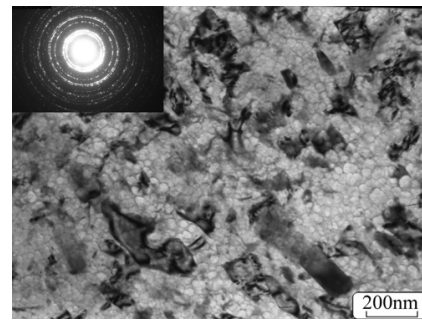

a

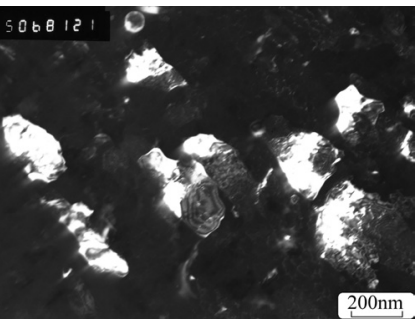

b
Pис. 2. Микроструктура сплава после кручения $(n=5)$ : (a) светлопольное изображение с микродифракцией; (b) темнопольное изображение в рефлексе матрицы.

Fig. 2. TEM microstructure after HPT $(n=5)$ : (a) bright field images with micro diffraction picture, (b) dark field image in the matrix reflection.

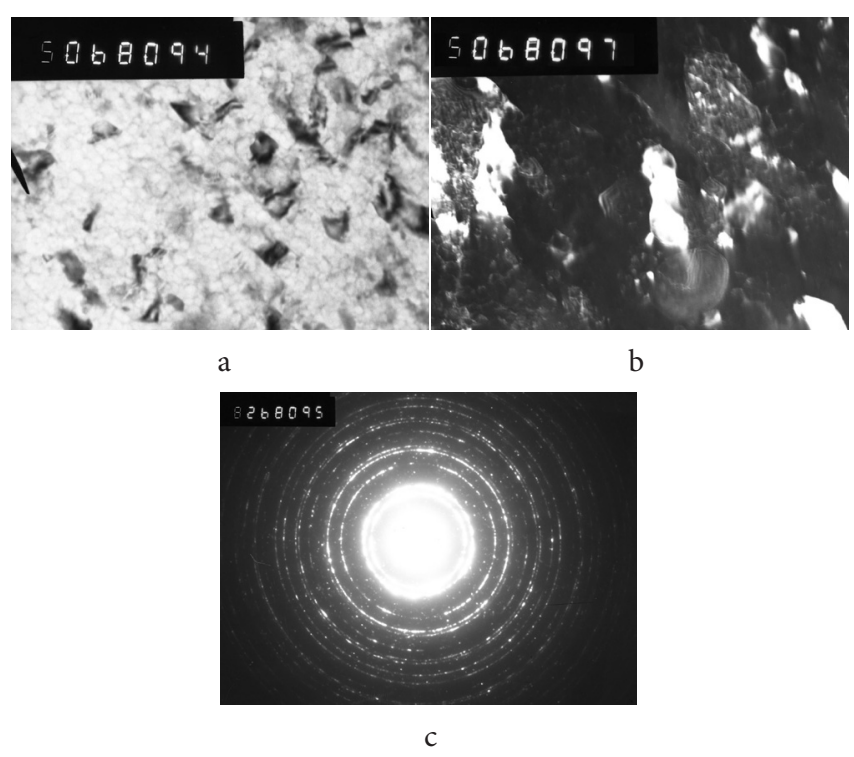

Pис. 3. Микроструктура сплава после кручения $(n=10)$ : (a) светлое поле; (b) темное поле в рефлексе матрицы; (c) микродифракция.

Fig. 3. TEM microstructure after HPT ( $n=10)$ : (a) bright field image; (b) dark field image in the matrix reflection; (c) micro diffraction picture. 
Несмотря на активную роль релаксационных процессов в сценарии формирования УМК сплава, его твердость, за счёт добавки к зернограничному упрочнению дисперсионной составляющей, достаточно высокая 3000 МПа.

\section{4. Заключение}

Показано, что в результате ИПД закалённого на твёрдый раствор крупнозернистого сплава формируется УМК рекристаллизованная структура с размером зерна 450 нм. При $e=6.5$ появляется дополнительный канал релаксации упругой энергии - динамическое старение пересыщенного Al твёрдого раствора, в результате которого твёрдость УМК сплава возрастает до 3000 МПа.

Установлено, что в процессе КВД предварительно состаренного сплава при $e=5.5$ образуется фрагментированная зеренно-субзеренная структура с высокой плотностью дислокаций, а при большей накопленной де-

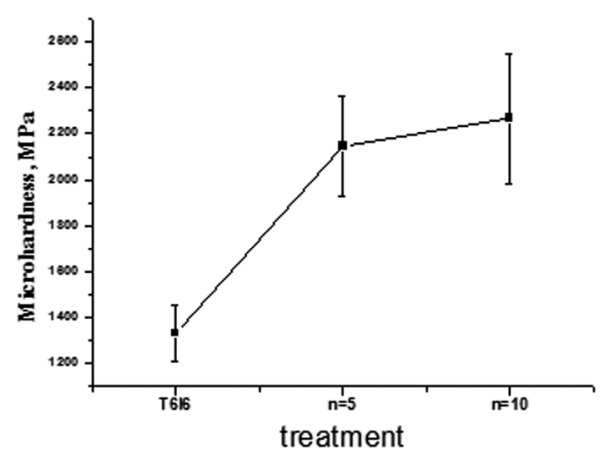

Рис. 4. Микротвердость сплава при разных обработках. Fig. 4. Microhardness of the alloy at different treatments.

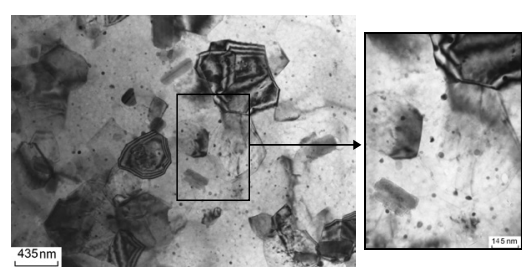

a

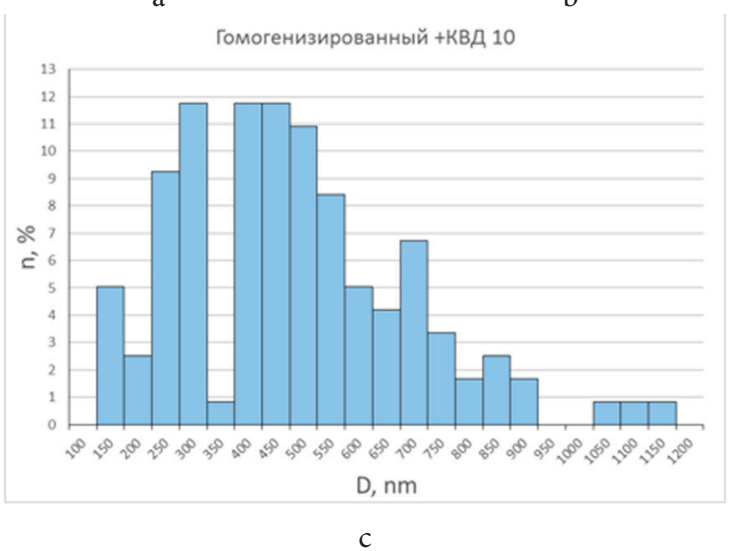

C

Рис. 5. Микроструктура закалённого сплава после КВД $(n=10):($ a) светлое поле (упрочняющая фаза); (b) темное поле в рефлексе матрицы; (c) распределение зёрен по размерам.

Fig. 5. TEM microstructure after HPT $(n=10)$ : (a) bright field image (hardening phase); (b) dark field image in the matrix reflection; (c) number fraction of grain size. формации параллельно развивается процесс динамического растворения частиц $S$ фазы, который сопровождается появлением бездефектных зерен и формированием смешанной УМК структуры. При $e=6.5$ формируется наноструктура с размером зерна 80 нм.

Электронно-микроскопические исследования выполнены в ЦКП ИФМ УрО РАН.

Благодарность/Acknowledgements: Pабота выполнена в рамках проекта ERA.Net.RUSPLUS S\&T-013 LightMat4Space. This work was supported by Scientific Research by Project ERA.Net.RUSPLUS S\&T-013 LightMat4Space.

\section{Литература/Reference}

1. N.A. Belov. Phases composition of commercial $\mathrm{Al}$ alloys. M.: MISiS (2010) 511p. (in Russian) [Н. А. Белов. Фазовый состав промышленных алюминиевых сплавов. М.:МИСиС. (2010) 511 с.].

2. D. G Eskin, J. Mater. Sci. 38,279-290 (2003).

3. S. C Wang. Int. Mater.Rev. 50,123-215 (2005).

4. L. Reich. Phil. Mag. Letters. 79,636-638 (1999).

5. R. N Lumley, I. J. Polmear, A. J. Morton Mater. Forum. 28, $85-95$ (2004).

6. Wu Y.E., Wang Y.T. Theoretical and Applied Fracture Mechanics. 54, 19-26 (2010).

7. Ł. Kaczmarek, M. Steglinski, H. Radziszewska, M. Kolodzeichik, Ya. Savicki, V. Shimanski, R. Atrashkevich, Ya. Svinyarski. Metalloved. Term. Obrab. Metal. 9, 45-50, (2012) (in Russian) [Л. Качмарек, M. Стеглински, Х. Радзишевска, М. Колодзейчик, Я. Савицки, В. Шимански, Р. Атрашкевич, Я. Свинярски. МИТОМ, 9, 45 - 50 (2012)].

8. E.D. Hafisova, I.R. Iskanderova, R. K. Islamgaliev, D. L. Pankrotov. Letters on materials. 5(4), 399-403 (2015) (in Russian) [Э. Д. Хафизова, И. Р. Искандерова, Р. К. Исламгалиев, Д. Л. Панкротов. Письма о материалах. 5(4), $399-403$ (2015)].

9. M.R. Gazizov, A. V. Dubina, D.A. Zhemchuzhnikova, R. O. Kaibyshev.. Phys. Met. Metallogr. 116(7), 718 - 729 (2015).

10. E.D. Hafisova, R.K. Islamgaliev, V.D. Sitdikova. Deformation and fracture of materials. 6, 25-29 (2015) (in Russian) [Э.Д. Хафизова, Р.К. Исламгалиев, В. Д. Ситдикова. Деформация и разрушение материалов. 6, 25 - 29 (2015)].

11. S. Sabbaghianrad, T.G. Langdon. Letters on materials 5(3), 335 - 340 (2015).

12. Ying Chen, Nong Gao, Gang Sha, Simon P. Ringer, Marco J. Starink Acta Materialia. 109, 202 - 212 (2016).

13. A. N. Petrova, H. Radziszewska, L. Kaczmarek, M. Klih, I. G. Brodova, M. Steglinski. Phys. Met. Metallogr. 117(12), 1237 - 1244 (2016)

14. T. S. Parel, S. C. Wang, M. J. Starink Materials and Design. 31(1), S2-S5 (2010).

15. I. G. Brodova, I. G. Shirinkina, A. N. Petrova, V. P. Pilyugin, T. P. Tolmachev. Phys. Met. Metallogr, 114(8), 667-671 (2013).

16. I. G. Brodova, I. G. Shirinkina, A. N.Petrova, O. V.Antonova, V.P. Pilyugin, Phys. Met. Metallogr. 111, 630-638 (2011). 